\title{
PERFORMANCE OF PLAN IRREGULARITY BUILDING USING RESPONSE SPECTRA ANALYSIS
}

\author{
Ranga swamy ${ }^{1}$, Raja Madhukar vishnu ${ }^{2}$ \\ ${ }^{1}$ Asst. Professor, Dept. of Civil Engineering, Nalla Malla Reddy Engineering College, RR Dist. Telangana \\ ${ }^{2}$ Structural Engineer, Murty \& Manyam Architects and Engineers, Banjara Hills, Hyderabad, Telangana.
}

\begin{abstract}
Earthquake leads to ground to vibrate and structures are subjected to severe stresses due to the motion. Today unsymmetrical building plan are quite common and reflects to torsion, discontinuous load path, lagging of stiffness and can be destructive. During earthquakes, plan irregular buildings will be more vulnerable. In order to avoid these failures, centre of stiffness and centre of mass of a building should come closer and need adequate stiffness so that torsion effect decreases. In the present study, attempt is made to understand the performance of G+40 storey high rise building considering steel bracing in various exterior positions by using response specturm analysis. The building plan is of $\mathrm{C}$ shape providing connection of bracing system within the storey, two storey, four storey and eight storey using $\mathrm{X}$ bracing system. The performance of building is compared considering with varying position of $\mathrm{X}$ - bracing and connectivity of storeys.
\end{abstract}

Key Words: Unsymmetrical plan, Steel bracings and response spectrum analysis.

$* * *$

\section{INTRODUCTION}

Structures will experience severe stresses due to earthquake and wind forces. The main aim of an engineer is to design a structure to resist forces with good stability and performance. Lateral forces can be resisted by providing shear wall, bracings etc,.

In braced frame structures lateral loading is resisted by diagonal members transforms the system into vertical girders where webs of vertical truss and columns acts as chords. Diagonal members provide high stiffness to the structure because horizontal shear is primarily absorbed, resist lateral forces by developing internal axial tensile or compressive actions and relatively small flexural actions. They help in reducing bending of columns, beams and also bypasses loads in transferring between columns. Beams act axially, when the system is a fully triangulated truss. They undergo bending only when the braces are eccentrically connected to them. Steel bracing can be connected by using various steel sections such as I- shaped sections, rectangular or circular tubes, single or double angles stitched together, T-shape sections, or channels.

The two important elements that concern to a structural engineer are the determination of seismic design forces and providing sufficient ductility. Structures can be analyzed by different methods such as linear static analysis, linear dynamic analysis, Non-Linear static analysis or Non-Linear dynamic analysis.

Linear static analysis or equivalent static analysis can be used for regular structures with limited height. Linear dynamic analysis can be performed in two ways, either by the response spectrum method or by the elastic time history method. The remarkable difference between linear static analysis and linear dynamic analysis is the level of the forces and their distribution along the height of the structure. Response spectrum method is applicable to the dynamic response of structures, which are asymmetrical or have areas of discontinuity or irregularity, in their linear range of behavior.

Raja Madhukar Vishnu, M.Prasanna Kumar and Y.Balakoti Reddy carried out research on linear static analysis and response spectrum analysis considering an unsymmetrical building plan of $\mathrm{T}$ shape and $\mathrm{G}+30$ storeys. They connected braces within the storey to the structure and concluded that $\mathrm{X}$, inverted $\mathrm{V}$ braces provides good stiffness control displacements but the time period decreases [12]. D. Yahiaoui considered research on the static non-linear pushover analysis of three and six storied RC structure considering different types of steel braces such as X, inverted V, ZX, and Zipper braces. They concluded that selection of section for steel bracing X, Zipper braces provides good results and improves the global capacity of building [1]. Marc Badoux and James O. Jirsa carried out experimental and analytical research on the retrofitting of steel bracing for RC frame under cyclic lateral loading and analytical study using DRAIN-2D software. They concluded that steel bracing is well suited for lateral strengthening of a multistorey RC structure from drift and collapse prevention [2].

Jose A. Pincheira, and James O. Jirsa conducted study on seismic performance on non-ductile reinforced concrete (RC) frames using inelastic static and dynamic response analyses for five ground motions representative of major earthquakes on firm and soft soil conditions of 3,7 and 12 storied RC frames using DRAIN-2D. Retrofit schemes included the installation of post-tensioned bracing, structural steel bracing, or infill walls of reinforced concrete. They concluded that, bracing systems the level of axial forces induced by steel braces would adversely affect the lateral strength of the existing reinforced concrete member[5]. T.Mahdi and V.Bahreini carried out the nonlinear seismic behavior of intermediate moment resisting frames with an 
unsymmetrical building plan of three, four and five storeys with infill walls. They concluded that infilled frames have high shear forces with small displacements [6]. M.R.Maheri, R.Kousari and M.Razazan conducted experimental research ductile RC frames with X and Knee braces. They concluded that $\mathrm{X}$ and Knee braces increases strength and capacity and decrease of global displacements. $X$ bracing provides good stiffness, but reduces ductility and Knee bracing provides desired ductility [7].

In the present study, behavior of plan irregularity of the $\mathrm{C}$ shaped building is considered. The effect of bracing in various positions and its connectivity to different floors is being studied. Displacements, time period, maximum storey drift, maximum torsion are discussed.

\section{ANALYTICAL INFORMATION}

In this study, a $\mathrm{G}+40$ storey building of $\mathrm{C}$ shaped is considered. The response spectrum analysis is carried out using the ETABS-2013 software. The modelling information and loading data is shown in table 1 and table 2 respectively. A typical plan of bracing positions for three different models is shown in Fig. 1, 2 and 3 respectively. With each model, bracing connectivity is varied from within the storey (Group 1), two storeys (Group 2), four storeys (Group 3) and eight storeys (Group 4) respectively is shown in Fig. 4

\section{RESULTS AND DISCUSSIONS:}

A response spectrum analysis is being carried out on bare frame and other three models with different bracing position in plan and connectivity with different floor levels using Etabs. Response specturm analysis is suitable for assymmetrical or have areas of discontinuity or irregularity, in their linear range of behavior. Top storey displacements, maximum storey drift, maximum storey torsion are compared with each group of graphs and results are tabulated.

Fig 5 and Fig 6 provides a graphical representation of displacements along $\mathrm{X}$ and $\mathrm{Y}$ direction respectively. Providing more stiffness to the structure controls displacements. From the figures we can observe that Model 3 has maximum stiffness and controls displacements, when compared with other models. Here displacements increases from Group 1 to Group 4 because the stiffness of the structure reduces comparatively.

Fig 7 shows a graphical representation of a time period. It is being found that in model 2 provides good results, when compared to other braced frame models. When stiffness of the structure is maximum, the time period is a minimum and vice versa. Providing adequate stiffness provides good ductility of the structure. Here when bracings are connected time period increases from Group 1 to Group 4. In Group 4 stiffness is less when compared to Group 1.

Fig 8 and Fig 9 provides a graphical representation of maximum storey drift along $\mathrm{X}$ and $\mathrm{Y}$ direction respectively. Providing more stiffness to the structure controls storey drift. From the figures we can observe that Model 3 has maximum stiffness and controls drift, when compared with other models. Here drift increases from Group 1 to Group 4 because the stiffness of the structure reduces comparatively. Fig 10 and Fig 11 shows a graphical representation of maximum storey torsion along $\mathrm{X}$ and $\mathrm{Y}$ directions respectively. Torsional moment is exposed, when there is any irregularity in building plan and increases when eccentricity increases. Providing adequate stiffness and mass to the structure, provide good results and controls torsional moment. It is being found that torsional moment is maximum in Group 2 and decreases from Group 3. In Group 4 torsion is comparatively less when compared to other braced models.

\section{CONCLUSIONS:}

The following are the observations from the present analysis.

1. Time period increases when connectivity of bracing is more than one storey. When bracings are connected for 8 storey's time period is maximum, with good ductile nature.

2. Torsion decreases when connectivity of bracing is more than one storey. Providing more stiffness and mass increases torsion, in Group 4 torsion is comparatively less when compared to other Groups.

3. Storey drift and displacement increases when connectivity of bracing is more than one storey. Here stiffness decrease when connectivity of bracing is more than one storey. In Group 1 stiffness is maximum when compared to other groups and controls drift and displacements.

The present analytical study shows that providing adequate stiffness and mass provides good ductile nature and control torsion.

\section{REFERENCES:}

Journal articles:

[1] A.Kadid and D.Yahiaoui, "Seismic Assessment of Braced RC Frames", Procedia Engineering, Volume No. 14, PP. 2899-2905, 2011.

[2] Marc Badoux and James O.Jirsa, "Steel Bracing for RC Frames for Seismic Retrofitting", Journal of Structural Engineering (ASCE), Volume No. 116 Issue No.1, pp- 5574,1990.

[3] A.murali Krishna and Dr.E.Arunakanthi "Optimum Location of Different Shapes of Shear Walls in Unsymmetrical High Rise Buildings", International Journal of Engineering Research and Technology Volume No.3 Issue No.9, ISSN 2278-0181,2014.

[4] T.Mahdi and V.Bahreini,"Seismic response of Asymmetrical Infilled concrete frames", Procedia Engineering, Volume No. 54, PP. 341-352, 2013.

[5] M.R.Maeri, R.Kousari and M.Razazan,"Pushover tests on steel X-braced and Knee braced RC frames", Engineering structures,

Books

[6] S.Bungale and Ph.D.S.E.Taranath, Wind and Earthquake Resistant Buildings Structural Analysis and Design, Marcel Dekker, 2005.

[7] S.K.Duggal, "Earthquake -Resistant Design of Structures”, Oxford University press, New Delhi, 2013. 
[8] Bureau of Indian Standards, IS 456:2000-code of practice for Plain and Reinforced Concrete, fourth revision, June 2000.

[9]Bureau of Indian Standards, IS 1893 (Part 1): 2002 criteria for earthquake resistant design of structures, fifth revision, June 2002.

[10]Bureau of Indian Standards, IS 800:2007 -code of practice for General Construction in Steel, third revision, December 2007.
Conference Proceedings

[11]Raja Madhukar Vishnu, M.Prasanna Kumar, Y.Balakoti Reddy,"Seismic Response of steel braced RC structure of Unsymmetrical building", International Conference On Advances in Civil Engineering Materials and Processes at Coimbatore Institute Of Technology during 7th,8th and 9th of January 2015.

Table 1: Modelling Information

\begin{tabular}{|c|c|}
\hline Height of the Each storey & $3.0 \mathrm{~m}$ \\
\hline Span along both $\mathrm{X}$ and $\mathrm{Y}$ directions & $5.0 \mathrm{~m}$ \\
\hline \multicolumn{2}{|c|}{ Material Properties } \\
\hline Grade of Concrete & M40 \\
\hline Grade of Steel & $\mathrm{Fe} 415$ \\
\hline Density of Concrete $\left(\mathrm{KN} / \mathrm{m}^{2}\right)$ & 25 \\
\hline Thickness of slab & 150 \\
\hline Beam Cross Section & $0.3 \mathrm{~m} \times 0.45 \mathrm{~m}$ \\
\hline \multirow{5}{*}{ Column Cross Section } & $0.9 \times 0.9($ GL to storey 4$)$ \\
\hline & $0.6 \times 0.9($ Storey $5+15)$ \\
\hline & $0.3 \times 0.9($ Storey $16+25)$ \\
\hline & $0.3 \times 0.75($ Storey $26+35)$ \\
\hline & $0.3 \times 0.6($ Storey $36+40)$ \\
\hline Steel Bracing Section & 2-ISA 200X200X25 \\
\hline
\end{tabular}

Table 2: Loading Data

\begin{tabular}{|l|c|}
\hline Live Load & $2 \mathrm{KN} / \mathrm{m}^{2}$ \\
\hline Floor Finish & $1.5 \mathrm{KN} / \mathrm{m}^{2}$ \\
\hline \multicolumn{2}{|c|}{ Seismic Loading Conditions } \\
\hline Zone & $\mathrm{V}$ \\
\hline Soil Type & Medium \\
\hline Importance Factor & 1 \\
\hline Response reduction & 5 \\
\hline \multicolumn{2}{|c|}{ Wind Loading Conditions } \\
\hline Wind Speed & $33 \mathrm{~m} / \mathrm{s}$ \\
\hline Terrain Category & 2 \\
\hline Structure Class & $\mathrm{B}$ \\
\hline Topography factor $(\mathrm{k} 3)$ & 1 \\
\hline
\end{tabular}




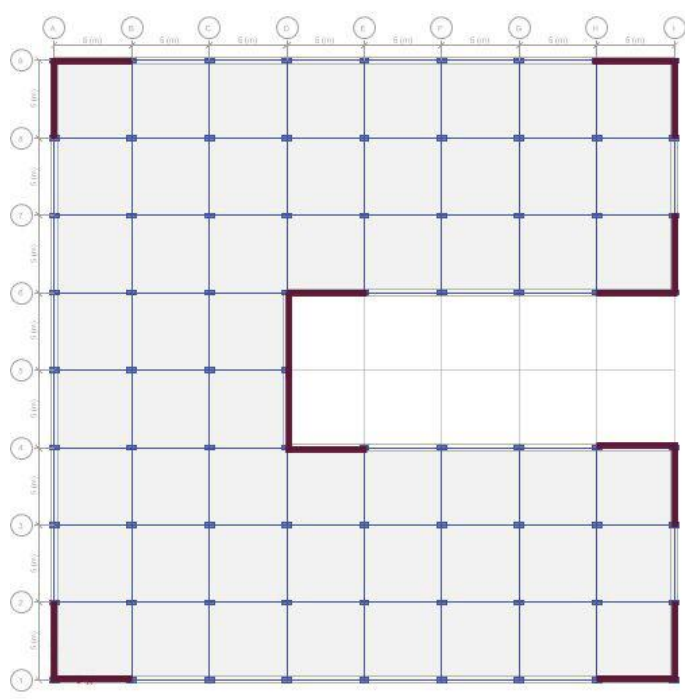

Figure 1: Top view of Model No.1

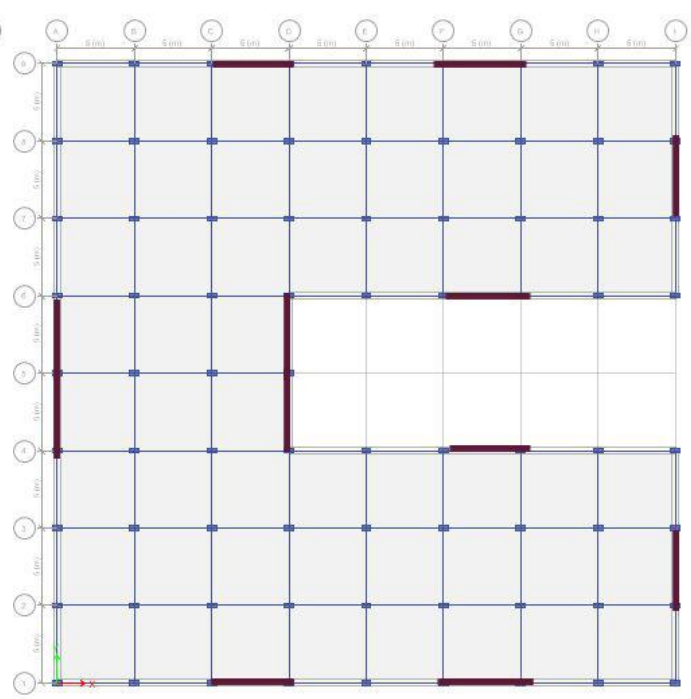

Figure 2: Top view of Model No.2

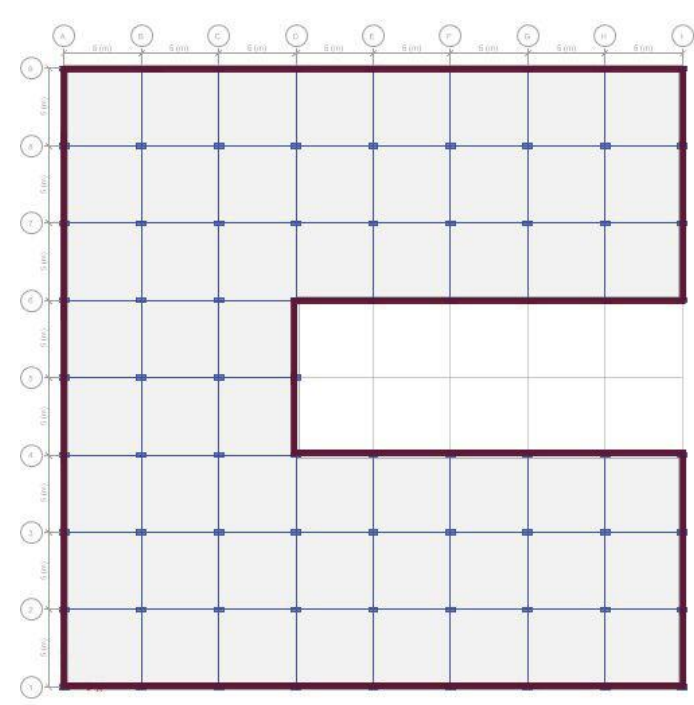

Figure3: Top view of Model No.3

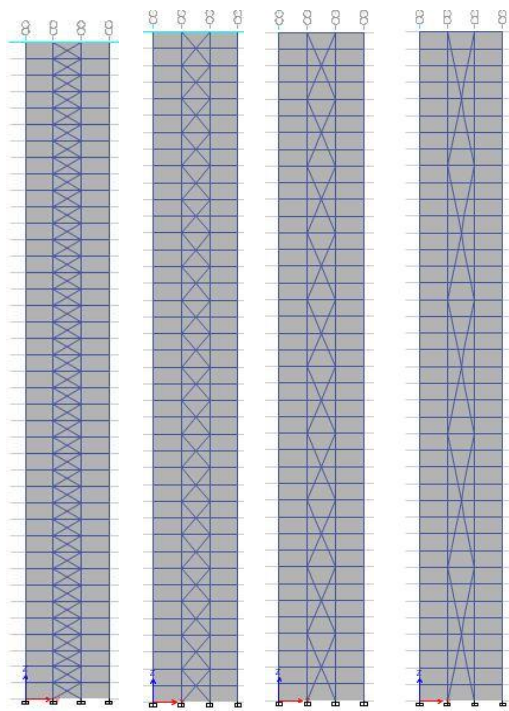

Figure4: Elevation view of Group1, Group 2, Group 3 and Group 4 


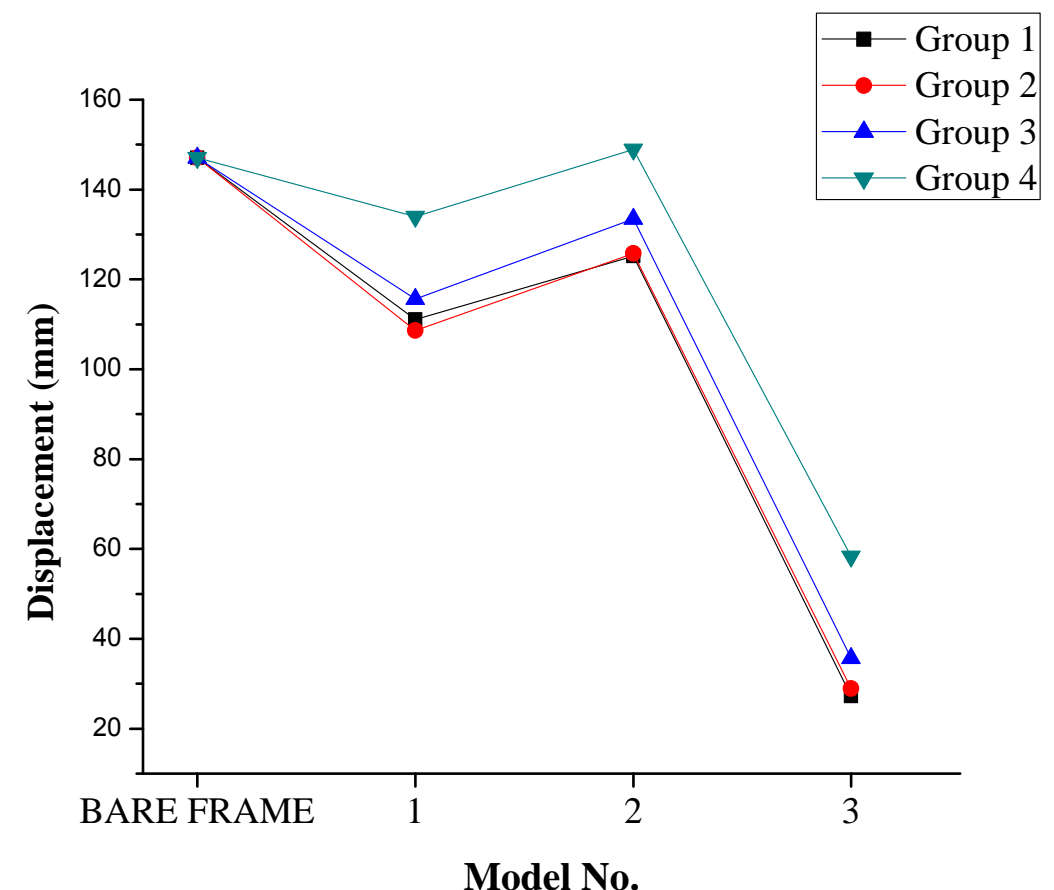

Figure 5: Displacement along (DL+EQX) load combinations

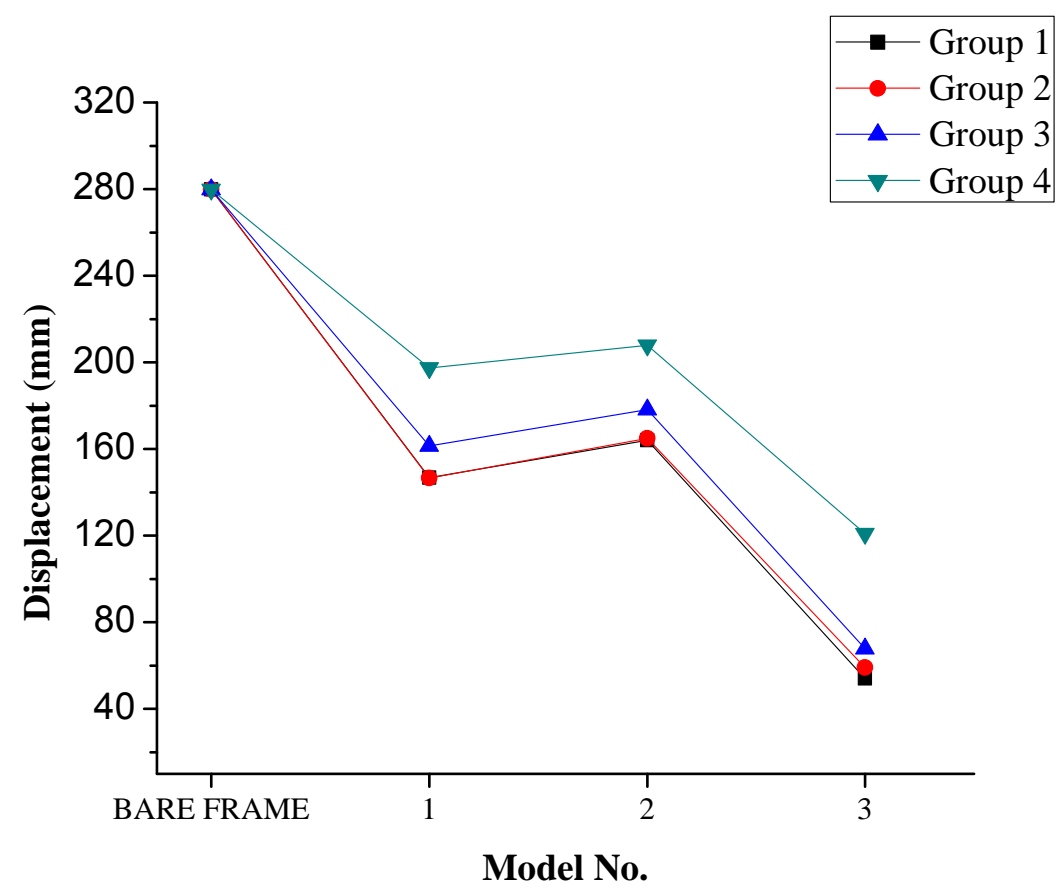

Figure 6: Displacement along (DL+EQY) load combinations 


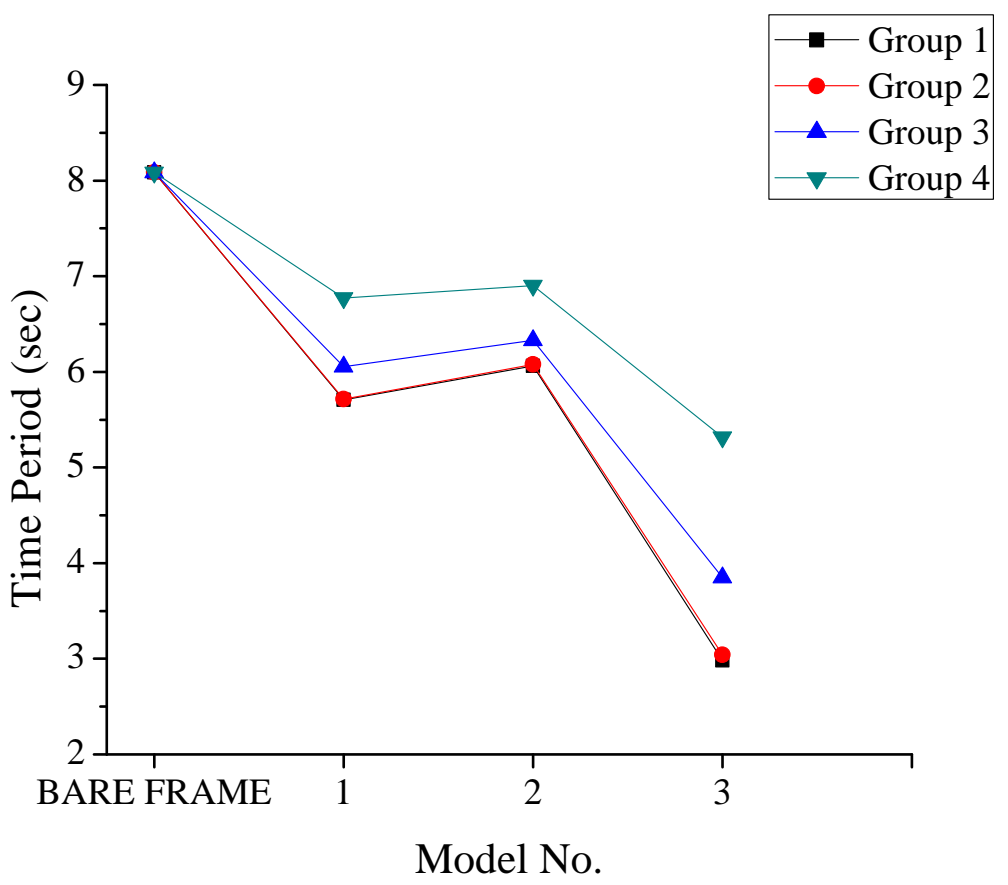

Figure 7: Time period

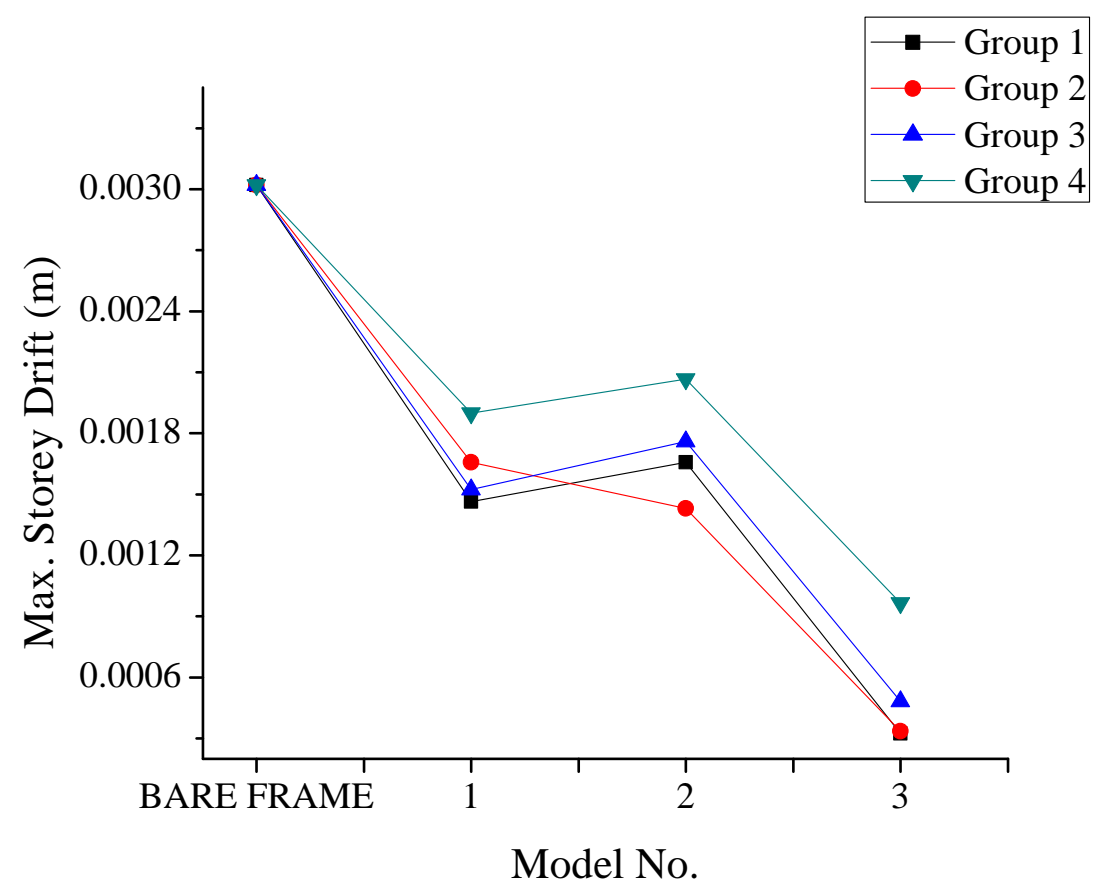

Figure 8: Max. Storey Drift along (DL+EQX) load combinations 


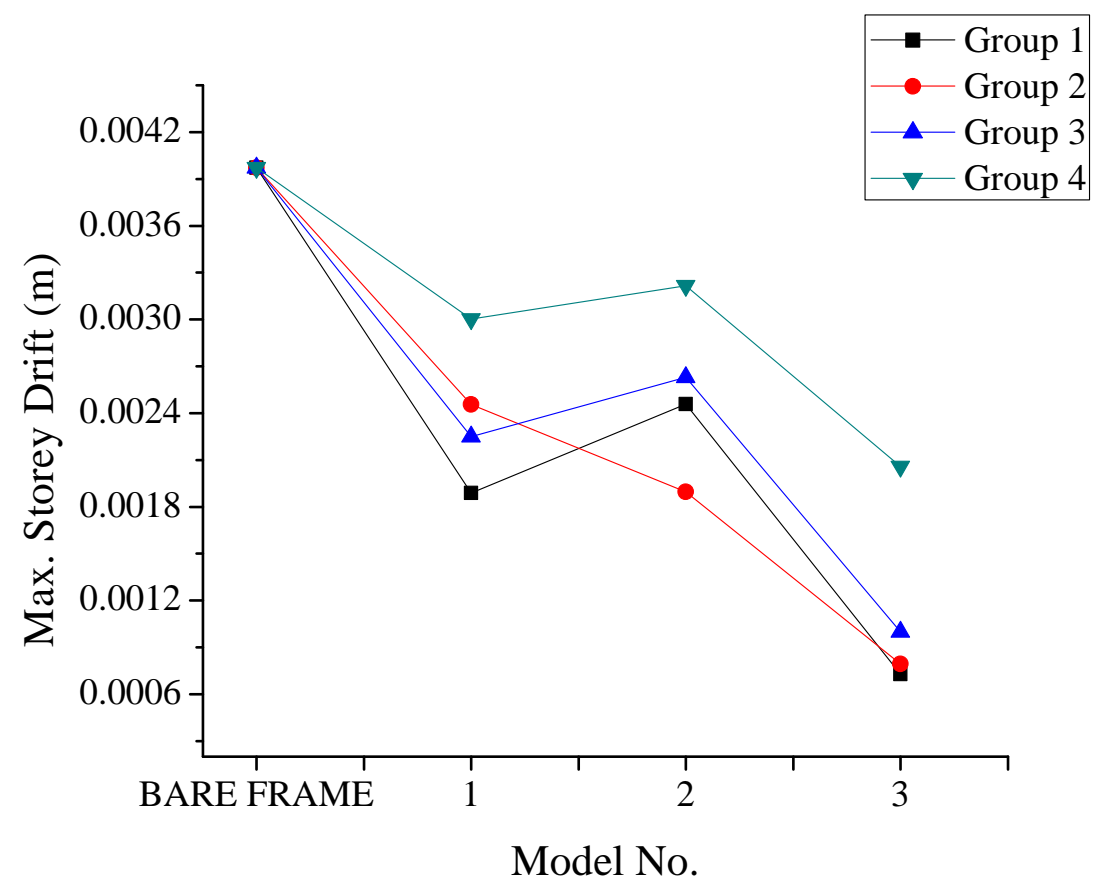

Figure 9: Max. Storey Drift along (DL+EQY) load combinations

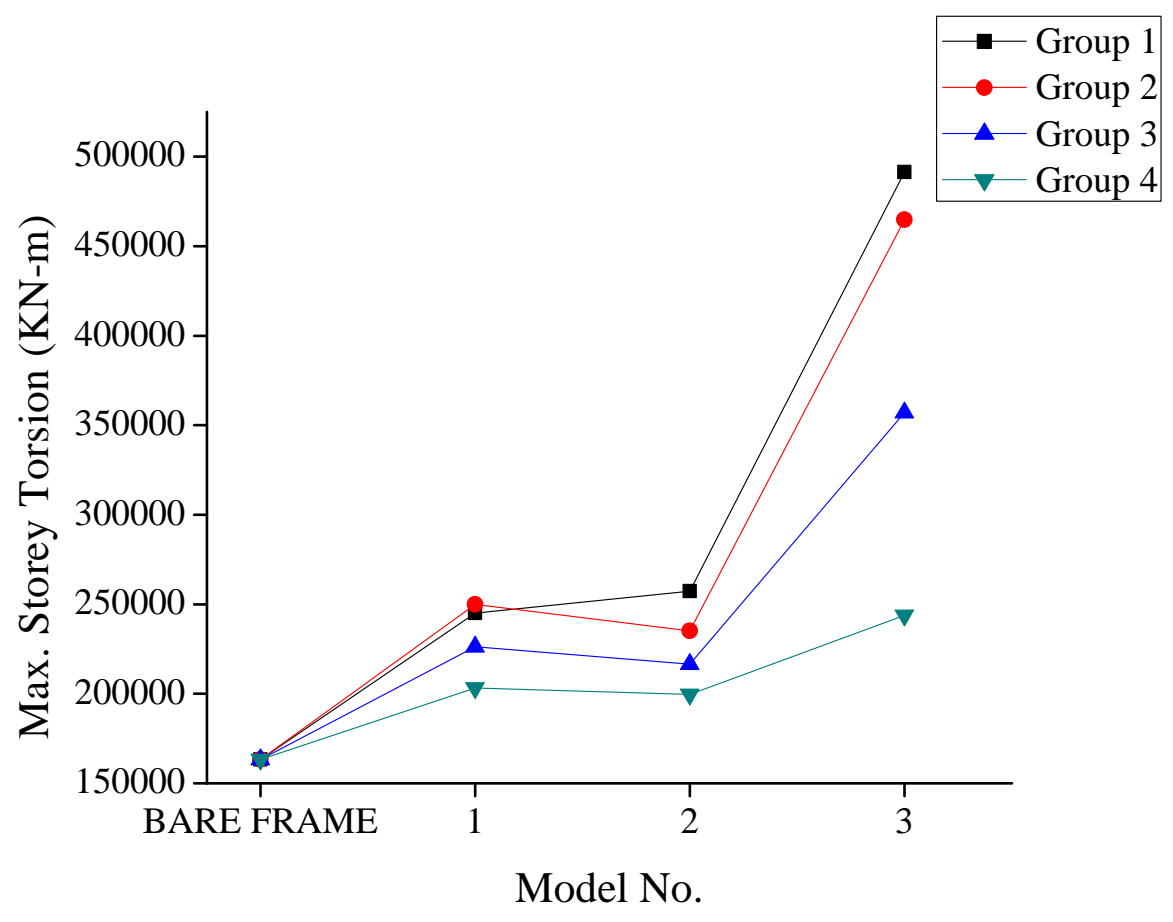

Figure 10: Max. Storey Torsion along (DL+EQX) load combinations 


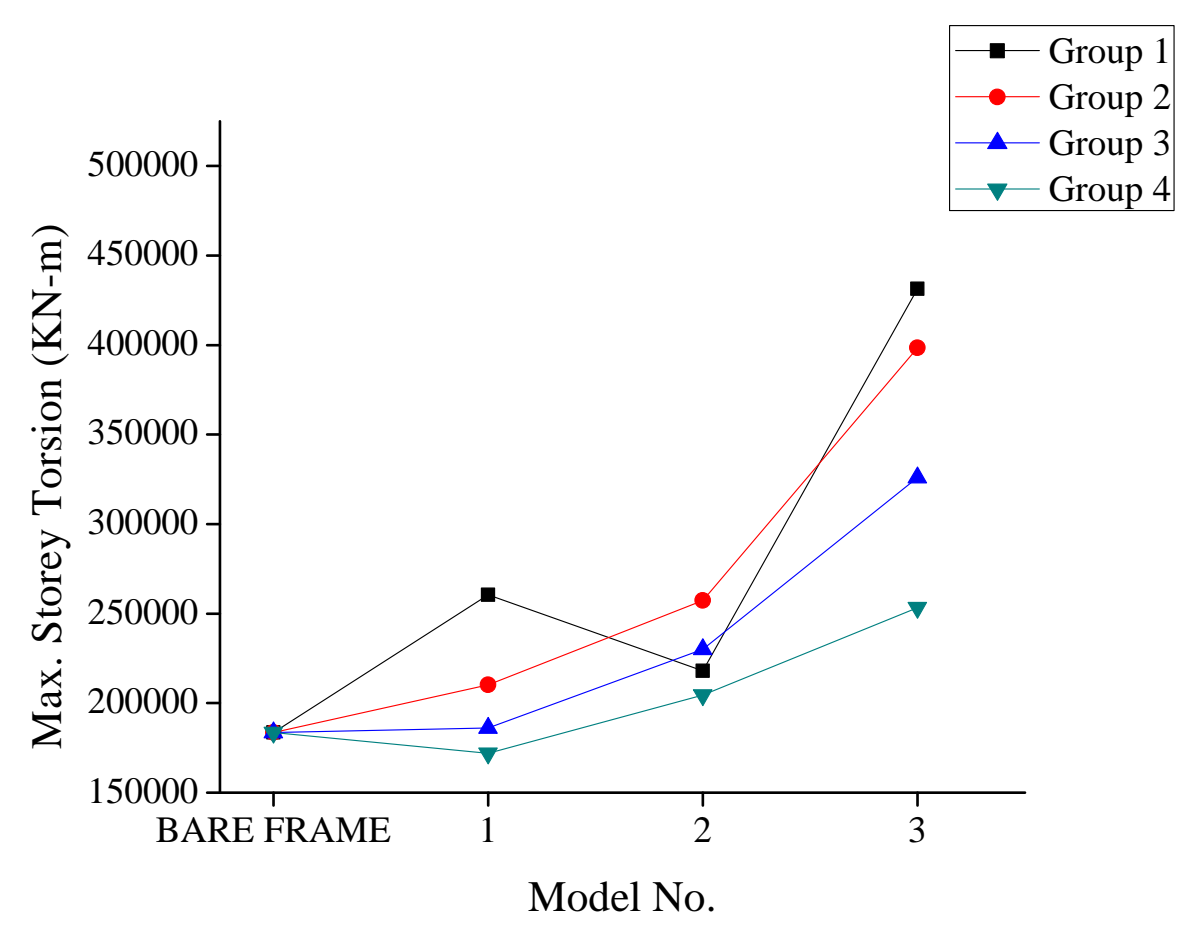

Figure 11: Max. Storey Torsion along (DL+EQY) load combinations 